\title{
Los trabajadores del conocimiento: activos de la empresa moderna
}

\author{
Dr. Juan PUELL PALACIOS
}

\section{RESUMEN}

Se considera que los trabajadores del conocimiento son dueños de los medios de producción que son los conocimientos que tienen como un patrimonio intelectual portátil y personal. Los trabajadores del conocimiento necesitan el empleo, mucho más de lo que el empleo los necesita a ellos. En este sentido podríamos decir que la empresa necesita a los trabajadores del conocimiento más de lo que ellos necesitan de la organización, pero esta necesidad tiene una relación simbiótica en la cual los dos se necesitan mutuamente. La empresa moderna debe atraer y conservar a los trabajadores del conocimiento que sean conceptuales como personas con sus conocimientos porque son los activos más valiosos de la organización.

Los trabajadores del conocimiento deben tener autonomía en el trabajo, porque cada uno de ellos lleva consigo su paquete individual de conocimientos que le permite saber más en su área específica, que cualquier otro en la organización. Esto significa que cada trabajador del conocimiento debe diseñar su propio campo de acción y asumir su responsabilidad y se le delegue plena autonomía.

En esta sociedad globalizada la gente que trabaja en las organizaciones, trabaja cada vez más con conocimientos que con destrezas. Debemos considerar que la destreza y conocimiento difieren en una característica fundamental: las destrezas o habilidades cambian muy lentamente, el conocimiento se cambia así mismo; un trabajador del conocimiento queda obsoleto sino vuelve a las aulas cada tres o cuatro años. Las personas cambian con el tiempo, convirtiéndose en personas diferentes, con diferentes necesidades, habilidades, perspectivas y, en consecuencia, tienen que "reinventarse" a sí mismo para entender la realidad para cambiarla o transformarla.

El desarrollo de la organización dependerá del trabajador del conocimiento para producir mayor riqueza, porque cada vez más la capacidad de supervivencia de las organizaciones estará ligada a su "ventaja comparativa", en otras palabras logran que el trabajador del conocimiento sea más productivo, que no solamente 
traerá cambios fundamentales en la estructura y naturaleza de las organizaciones, si no también del sistema económico.

Estamos viviendo conjuntamente con las organizaciones en una sociedad llamada "Sociedad del Conocimiento" que tiende a ser más competitiva globalmente. La sociedad futura será una sociedad del conocimiento que tendrá las siguientes características:

1) La carencia de fronteras, porqué el conocimiento viaja aún más fácilmente que el dinero,

2) La modalidad hacia arriba, disponible para todo el mundo, a través de la educación formal, fácilmente adquirible.

3) El potencial para el fracaso lo mismo que para el éxito. Cualquiera puede adquirir los "Medios de Producción", es decir, el conocimiento requerido para el empleo, pero no todos pueden ganar.

Esta sociedad del conocimiento será forjada por los trabajadores del conocimiento en todos los niveles de competitividad para las organizaciones como para los individuos.

El conocimiento sin habilidad es improductivo, por esta razón el "trabajador del conocimiento" se utiliza para describir a las personas con considerable aprendizaje o conocimientos teóricos que tienen los médicos, administradores, abogados, economistas. Pero el conocimiento más notable sucederá en las "Tecnologías del Conocimiento" que poseen los técnicos informáticos, diseñadores de software, laboratoristas clínicos, tecnólogos industriales y otros. Los trabajadores del conocimiento que trabajan en las tecnologías del conocimiento gastan más tiempo trabajando con las manos que con su cerebro. De este modo el conocimiento no elimina la habilidad, por el contrario, el conocimiento está convirtiéndose rápidamente en la base de la habilidad.

Cada vez más el conocimiento se utiliza para que las personas adquieran habilidades de muy avanzada clase, más rápida y garantice el éxito personal. Solamente, cuando el conocimiento se usa como base de la habilidad se vuelve productiva, por sí sólo, el conocimiento especializado no produce nada. El conocimiento puede llegar hacer productivo sólo cuando está integrado a una tarea, y por eso la sociedad del conocimiento es también una sociedad de organizaciones, porque el objetivo y función de una organización sea empresarial o no, es la integración de conocimientos especializados en tareas comunes.

Los intelectuales ven a la organización como una herramienta, que les permite practicar su TECHNE o conocimiento especializado. Los gerentes ven al co- 
nocimiento como medio para lograr los fines de la organización, ambos tienen razón, son opuestos, pero se relacionan entre sí, como polos más que como contradictores. Si los dos se equilibran entre sí, puede nacer la creatividad, orden, cumplimiento y misión.

El trabajador del conocimiento posee el medio de producción que es su propio conocimiento y los gerentes más progresistas aplican dicho conocimiento para que los trabajadores dirijan sus acciones hacia los objetivos o metas. Los gerentes deben comprender que gerenciar es mucho más que ejercer un rango o privilegio; es mucho más que hacer negocio. Gerenciar afecta a las personas y sus vidas. El reto será hacer productivos a los trabajadores del conocimiento, incluso se requiere conocimiento teórico altamente avanzado para lograr altos niveles de productividad.

\section{BIBLIOGRAFÍA}

1. Cuevas, Carlos Gutierrez Gestión del Conocimiento. Edit. Ciudad Real España. K.M.C - 2004.

2. Drucker, Peter La Gerencia: Tareas, Responsabilidades y Prácticas. Edit. ATENEO - 1992.

3. Drucker, Peter Gestión del Conocimiento. Edit. DEUSTO-2007.

4. Molina Gonzales, José Luis Gestión del Conocimiento en la Organizaciones. Edit. Negocios, Empresas y Negocios - 2009. 